\title{
A Portable Sonified Neurofeedback Therapy for Autism Spectrum Disorder Patients-An Initial Evaluation
}

\author{
Adrian Attard Trevisan ${ }^{1 *}$, Paolo Cavallari' ${ }^{1}$ and Frederick Attard ${ }^{2}$ \\ 1 Università Degli Studi di Milano, Milano, Italy \\ ${ }^{2} R \& D$ Department, AAT Research Ltd, Marsa, Malta, Italy
}

\begin{abstract}
A novel sonified Neurofeedback management therapy for children diagnosed with Autism Spectrum Disorder (ASD) is explored and tested. ASD is a condition in children which effects their social interaction, language and communication and behaviours. Literature suggests that people diagnosed with ASD tend to have higher levels of Delta $(\delta)$ waves and less levels of Alpha $(\alpha)$ and Beta $(\beta)$ waves in their brain activity. This paper studies how the use of sonified Neurofeedback produced by a two channel EEG device headband and the Brain Music System (BMS), can successfully suppress the $\delta$ waves while at the same time promote $\alpha$ and $\beta$ waves. The two channel EEG device headband records EEG activity and the BMS converts the EEG activity into sonified binaural signals feeding them back to the user. Results recorded showed a relevant $\delta$ wave suppression clearly indicating that children subjected to this study made significant progress in managing symptoms associated with ASD. This was also confirmed by feedback from the parents of the respective subjects.
\end{abstract}

Keywords: EEG; Sonified neurofeedback; Autism spectrum disorder

\section{Introduction}

\section{Problem statement}

In this paper, a research study is performed on an experimental management treatment possibility to Autism Spectral Disorder (ASD) making use of musical Neurofeedback (NF). The Brain Music System (BMS) was used in conjunction with a two channel electroencephalography (EEG) device headband with the intent to suppress Delta $(\delta)$ waves in the subject's brain.

\section{Autism spectral disorder}

ASD is a disorder characterized by impairments in social interaction, verbal communication and repetitive behaviours (European Commission [1]). It affects around 60 children out of 1000 [2], of which mostly are below the age of 8 years. No treatment has been found to cure ASD, however, the disorder is controllable with the use of several treatment methodologies [1]. In the literature reviewed we see how several treatments tend to improve the patients' life leading to the point where the child grows up to live a normal or near normal life [1].

There are two main types of treatments for ASD; Ingestible (orally administered e.g. taking pills) and noningestible (externally administered e.g. psychiatry) [3]. Studies indicate that the most effective noningestible treatments are specialized and supportive educational programs tailor-made for children suffering from ASD [3,4]. In fact, one of the most effective specialized programs is speech and language therapy [5].

The only Food and Drug Administration (FDA) approved medication for ASD treatment are Risperidone and Aripiprazole and are only approved to be used in children between the ages of 5 and 16 [3]. Any other medication used in treating ASD are targeted to treat secondary effects caused by ASD such as sleep deprivation, hyperactivity, anxiety, aggression, disruptive behaviour and selfinjuries [3]. However, these sort of ingestible therapies are known to cause several other problems and side effects [3].

Literature suggests that children diagnosed with ASD have different brain activity levels when compared to normally developing children. A study on 50 children (27 diagnosed with ASD and 23 controls) concluded that children with ASD have higher levels of $\delta$ waves amongst other abnormalities which support the imbalance of neural excitation in an Autistic brain [6].

\section{Neurofeedback}

NF has now been used for several years in research, clinical trials and as treatment for several conditions and disorders [7]. NF makes use of the user's EEG gathered data to modify the neurophysiological and neurological basis for a number of neurological based disorders [7]. NF proved to be helpful for a number of neurological disorders $[8,9]$. Research on the effects of NF performed on patients diagnosed with ASD show that improvements in social behaviour and electrophysiological behaviour are obtained in several cases $[3,10]$. Other research studies imply that NF has no or little effect in treating ASD [11].

\section{Two channel EEG device and the Brain Music System}

As a preamble to the analysis of obtained results a general introduction on the two channel EEG device headband and the BMS is presented. The two channel EEG device headband developed by AAT Research, is a portable two electrode EEG signal acquisition device which uses a modified version of the low resolution brain electromagnetic tomography (LORETA) to obtain estimates of subcortical activity. This device can connect to a computer via Bluetooth such that it can be interfaced to the BMS application running on the same machine. The BMS is a software application that uses Sonified Neurofeedback to convert the EEG signals obtained from the headband into Sonified

*Corresponding author: Adrian Attard Trevisan, Università Degli Studi di Milano Milano, Italy, Tel: 0035679843767; E-mail: adrian.adtard@unimi.it

Received August 20, 2013; Accepted September 18, 2013; Published September 21, 2013

Citation: Trevisan AA, Cavallari P, Attard F (2013) A Portable Sonified Neurofeedback Therapy for Autism Spectrum Disorder Patients-An Initial Evaluation. J Neurol Disord 1: 133. doi:10.4172/2329-6895.1000133

Copyright: (C) 2013 Trevisan AA, et al. This is an open-access article distributed under the terms of the Creative Commons Attribution License, which permits unrestricted use, distribution, and reproduction in any medium, provided the original author and source are credited. 
signals (binaural beats). These musical waveforms are presented back to the user forming a loop in attempt to level the brainwaves in realtime according to the respective mental state [12]. The NF music trains the brain in attaining a pleasant frequency of brain activity $[13,14]$.

The basic composition of the whole system used as therapy is represented by a detailed block diagram in Figure 1.

EEG is the measure of the electrical activity of the brain and is widely represented using the LORETA algorithm [15]. The LORETA algorithm was first introduced in 1994 as 3D, linear solution to the inverse EEG/MEG problem [16].

The two-channel EEG headband device makes use of just two dry electrodes; one placed on the frontal left hemisphere and the other placed on the frontal right hemisphere of the subject's head to collect EEG data [13,14]. The signal gathered from the electrodes is processed using a modified version of the LORETA algorithm $[13,14]$. The latter mentioned algorithm uses the EEG data gathered from the two electrodes to predict, estimate and virtually create 14 other channels. The output data from the EEG headband device is saved in EDF file format (which is the European Standard EEG data file format) $[13,14]$.

\section{Aims and objectives}

The aim of combining the two channel EEG device and BMS is to create a user friendly, portable and reduced cost platform as an aid to people diagnosed with ASD. Such a person would generally have increased levels of $\delta$ waveforms when awake, which are normally found in a healthy person's brain activity sleep patterns. The BMS aims to suppress $\delta$ waveforms while promoting Alpha $(\alpha)$ and Beta $(\beta)$ waves, which are respectively associated with focus and mental activity. The intention of this study is to analyse the effect of the two channel EEG device and the BMS combined together over a group of subjects diagnosed with ASD.

\section{Testing}

\section{Two channel EEG device SNR testing}

A coherence test was carried out on the two channel EEG device headband in a sterile clean room environment. The test was performed using the in-house clean room for a sterile environment, a dBA (sound Amplitude) meter, a set of speakers which could be calibrated to produce a certain $\mathrm{dBA}$ sound and tailor-made software designed to produce pure tone sounds at various frequencies while recording the response from the two channel EEG device sensors.

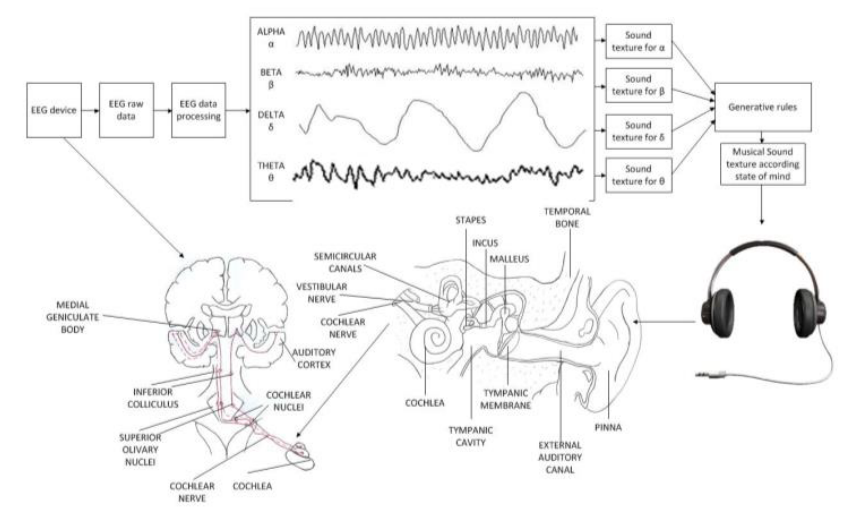

Figure 1: Block diagram of the Brain Music System used as a Neurofeedback therapy.

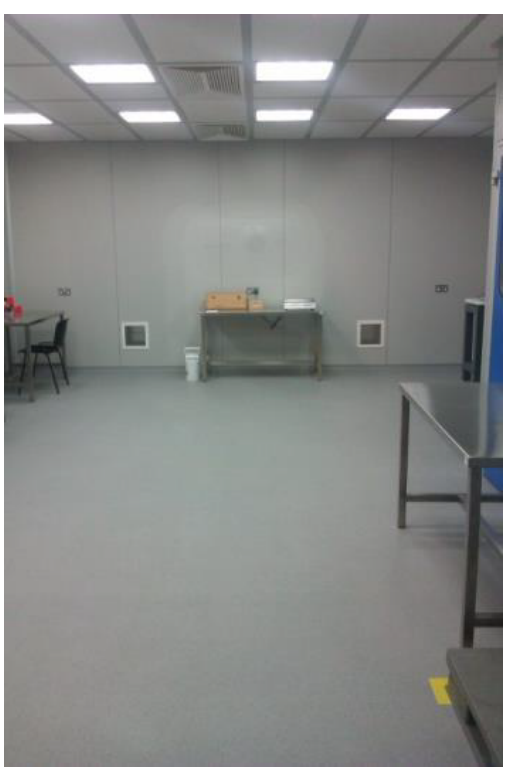

Figure 2: Sterile environment used for testing procedure.

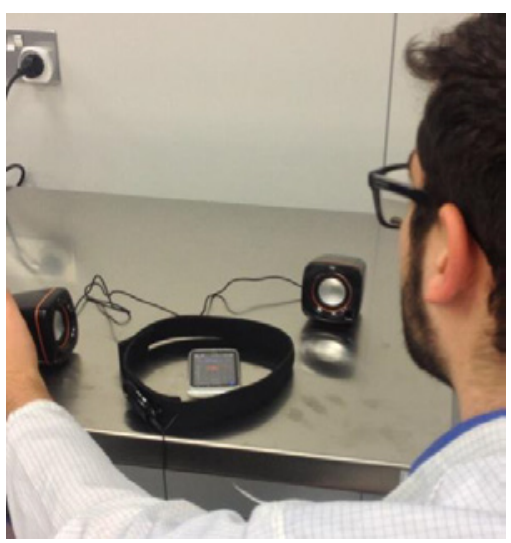

Figure 3: Testing setup.

The test was carried out by recording readings from the headband while pure tones at frequencies $256 \mathrm{~Hz}, 512 \mathrm{~Hz} 1 \mathrm{kHz}, 3 \mathrm{kHz}, 5 \mathrm{kHz}, 7$ $\mathrm{kHz}$ and $10 \mathrm{kHz}$ were played sequentially. The whole testing procedure was repeated twice at $80 \mathrm{~dB}$ amplitude and $92 \mathrm{~dB}$ amplitude. In addition, a reading was also taken of background noise since perfect silence in the clean room could not be obtained and thus the background noise was common in all readings. This background noise was found to have an amplitude of $57 \mathrm{~dB}$. The recorded signals from the two channel EEG device sensors were saved and used for analyses.

Seven plots were obtained from the results gathered. Each plot was constructed from background noise data and the response of the device at $80 \mathrm{dBA}$ and $92 \mathrm{dBA}$ for each frequency respectively (Figures 2-4).

Figure 5 shows some of the several plots constructed. These prove that the output recorded with respect to different $\mathrm{dBA}$ and same frequency input tone, is coherent. This validates the results that the sensor produces.

\section{Participant selection}

For a subject to be considered to participate in this long term 
Citation: Trevisan AA, Cavallari P, Attard F (2013) A Portable Sonified Neurofeedback Therapy for Autism Spectrum Disorder Patients-An Initial Evaluation. J Neurol Disord 1: 133. doi:10.4172/2329-6895.1000133

Page 3 of 14

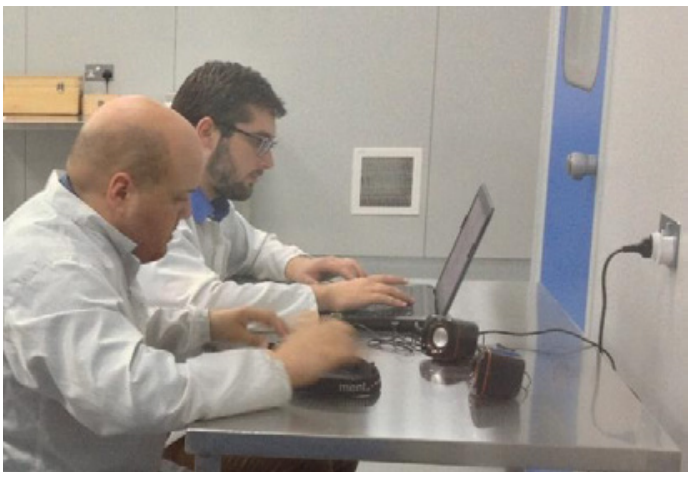

Figure 4: Testing procedure.

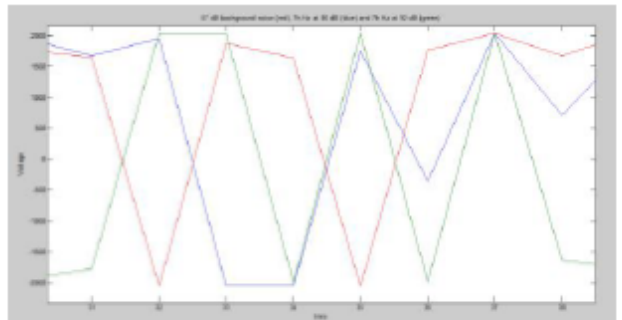

(a)

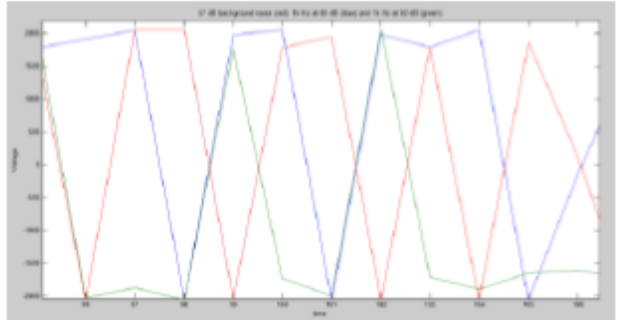

(b)

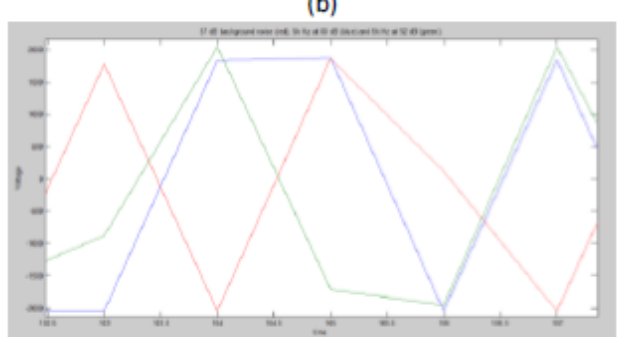

(c)

Figure 5: Plotting outputs of the same frequency tones at $80 \mathrm{~dB}, 92$ $\mathrm{dB}$ and $57 \mathrm{~dB}$ background noise for (a): $7 \mathrm{k} \mathrm{Hz},(\mathrm{b}): 1 \mathrm{k} \mathrm{Hz} \mathrm{\&} \mathrm{(c):} 5 \mathrm{k} \mathrm{Hz}$.

clinical trial a number of requirements had to be met. This was done with reference to participant selection done for Autistic clinical trials performed by the U.S. National Institutes of Health [17] and a similar clinical trial selection process to that performed by the Yukon Government (Canada) for clinical trials [18].

To be eligible for the clinical trial presented, the following requirements had to be met:

Age: Between 2 Years and 40 Years

Gender: both
The participant had to be diagnosed with ASD or Asperger's Disorder.

Participants were considered as non-eligible if they suffered from hearing impairment.

\section{Presentation of test data}

The test considered in this paper is based on nine subjects using the two channel EEG device and BMS in unknown non-controlled environment such as the test subject's personal household. Participants in this study signed a disclaimer and submitted their reports daily. No remuneration was given to the subjects in this study. Also, none of the members of the staff had direct access to both the subjects and their reports respectively.

Participants in this study are all aged between 6 and 18 years and have all been diagnosed with ASD, although the severity of the condition's diagnosis varies from Pervasive, Asperger's Syndrome to Classical Autism. Since the subjects submitted their reports voluntarily, the regularity of BMS report submission, as well as the total amount of reports submitted varies with the test subject. Due to possible variability in the data and amount of data sets between subjects, the obtained BMS reports are not analysed across subjects but analysis of test results is performed on each data set independently.

Nine subjects were in accordance to the participant selection policy employed in this study; however, only eight were accepted while the other subject was eliminated due to the lack of reports submitted. The first 10 session reports of each participant were not considered for analysis in order to give the participants enough time for adaptation.

Furthermore, from all eight accepted subjects, the focus of analysis was done on a particular one of them. This is due to the highest testing data reports obtained from the subject. A total of 124 reports were submitted for analysis from this particular subject.

\section{Procedure}

Each session accepted for analysis in this paper involves the test subject's usage of the two channel EEG device and the BMS for a fixed 40 minute pre-programmed session for not more than once per day. Such a session involves the user wearing the two channel EEG device headband with the two electrodes placed symmetrically on the frontal lobe. The user then connects to the BMS and undergoes a session while sitting down and wearing headphones. Furthermore the user was asked to minimize eye blinking and movement in order to reduce artefact generation on the EEG signal obtained. As the session ends, the user is provided with a report in Portable Document Format (PDF). This document is conveyed to AAT Research and analysis is performed on the waveforms presented in this report. These PDF type reports were converted to a Portable Network Graphics (PNG) type of image in order to extract data from the PNG images using image processing techniques. To do this, an algorithm was built in which a set of PNG report images were selected for analysis. Each report was cropped in such a way that only $\alpha, \beta$ and $\delta$ waves are left of the original report image. The image now obtained, has a binarization procedure performed on the respective red (R), green $(G) \&$ blue (B) images using a threshold of 0.86 . This provided us with images of $\alpha, \beta \& \delta$ waveforms independently. The respective waveform images' bounding box coordinates were detected and each image was scanned horizontally to detect the amount of voltage peaks occurred during the respective session of every wave type i.e. $\alpha, \beta \& \delta$. A peak is defined as a rapid change in voltage from baseline voltage exceeding a certain threshold set. 
Citation: Trevisan AA, Cavallari P, Attard F (2013) A Portable Sonified Neurofeedback Therapy for Autism Spectrum Disorder Patients-An Initial Evaluation. J Neurol Disord 1: 133. doi:10.4172/2329-6895.1000133

Page 4 of 14

Moreover, parents of the children participating in this study were given a question to answer to have direct feedback on the progress of the child using the two channel EEG device headband and BMS system.

\section{Results}

Refer to (Tables 1-4) and (Figures 6-22).

\section{Analysis and Discussion}

$\delta$ waves, which in a healthy normal person are recorded during deep sleep (stage 3 \& stage 4) [19], tend to be at high levels at all times in persons diagnosed with ASD, even while they are awake [19]. In a study done to compare normally developing children and children diagnosed with ASD, it was concluded that brain asymmetry activity in children with ASD is caused by higher $\delta$ wave activity [20]. With reference to this result, in the presented study, $\delta$ waves are being suppressed. Suppression of these $\delta$ waves could be seen in Figure 22 .

Results displayed in Figures 14,15 and 22 show how $\delta$ wave peaks tend to have lowered in peak levels in the respective time in which the respective subject is using the 2 channel EEG headband with the BMS. A significant improvement could be seen when comparing the $\delta$ peak levels in the first session to that in the last session reported.

Analyzing Figures 16,17 and 20, we can conclude that during the periods in which the subjects are being analyzed, all participants tend to have increased levels of a wave peaks over time. a waves are produced in state of relaxation and closing eyes [19]. As a result, it could be concluded that the subjects being studied in this paper tend to be more relaxed over time. With reference to the cause of lateral asymmetry in

\begin{tabular}{|c|c|c|}
\hline Gender & Medical Condition & $\begin{array}{l}\text { Specify your experience on the therapy's } \\
\text { effectiveness }\end{array}$ \\
\hline Male & Autism & $\begin{array}{l}\text { More attention, more calm, less tantrums, but zero } \\
\text { improvement in speech }\end{array}$ \\
\hline Female & Autism & $\begin{array}{l}\text { Longer concentration span, happier, calmer, } \\
\text { shows affection, acceptance of peers and siblings } \\
\text { respects parents, Obedient etc... }\end{array}$ \\
\hline Male & ASD & $\begin{array}{l}\text { Our son seems to have calmed down after several } \\
\text { sessions }\end{array}$ \\
\hline Female & $\begin{array}{l}\text { Mild Asperger's } \\
\text { Syndrome }\end{array}$ & Needs more time to see effectiveness \\
\hline Male & ASD & $\begin{array}{l}\text { I noticed that our son has increased in his } \\
\text { vocabulary a lot and is now communicating much } \\
\text { better. Now he can also describe a situation that } \\
\text { happened when we were not present. Actually he } \\
\text { is now enjoying communicating. In the past few } \\
\text { days he also started to decide what he wants and } \\
\text { communicate his decisions too, which is a very } \\
\text { positive step. }\end{array}$ \\
\hline Female & PDD & Increased academically \\
\hline
\end{tabular}

Table 1: Parents feedback

\begin{tabular}{|l|l|l|l|l|l|l|}
\hline Subject & $\begin{array}{l}\text { Alpha } \\
\text { Before }\end{array}$ & $\begin{array}{l}\text { Alpha } \\
\text { After }\end{array}$ & $\begin{array}{l}\text { Beta } \\
\text { Before }\end{array}$ & Beta After & $\begin{array}{l}\text { Delta } \\
\text { Before }\end{array}$ & $\begin{array}{l}\text { Delta } \\
\text { After }\end{array}$ \\
\hline 1 & 652 & 1960 & 801 & 1452 & 506 & 322 \\
\hline 2 & 515 & 775 & 1066 & 789 & 1235 & 1019 \\
\hline 3 & 15 & 6 & 28 & 78 & 164 & 149 \\
\hline 4 & 917 & 140 & 850 & 653 & 857 & 107 \\
\hline 5 & 6 & 309 & 50 & 1201 & 729 & 470 \\
\hline 6 & 640 & 251 & 586 & 981 & 535 & 377 \\
\hline 7 & 907 & 28 & 166 & 160 & 946 & 206 \\
\hline 8 & 1088 & 485 & 1514 & 631 & 984 & 441 \\
\hline
\end{tabular}

Table 2: Before and after Alpha, Beta and Delta peak levels. This data was used for statistical analysis to test the significant change over the period of time the BMS was used.

\begin{tabular}{|c|c|c|}
\hline \multicolumn{3}{|c|}{ Paired t-Test for Before and After Alpha } \\
\hline & Alpha Before & Alpha After \\
\hline Mean & 592.5 & 494.25 \\
\hline Variance & 162717.4286 & 414583.9286 \\
\hline Observations & 8 & 8 \\
\hline Pearson Correlation & 0.098090614 & \\
\hline Hypothesized Mean Difference & 0 & \\
\hline df & 7 & \\
\hline t Stat & 0.383037635 & \\
\hline $\mathrm{P}(\mathrm{T}<=\mathrm{t})$ one-tail & 0.356529119 & \\
\hline t Critical one-tail & 1.894578605 & \\
\hline $\mathrm{P}(\mathrm{T}<=\mathrm{t})$ two-tail & 0.713058238 & \\
\hline t Critical two-tail & 2.364624252 & \\
\hline \multicolumn{3}{|c|}{ Paired t-Test for Before and After Beta } \\
\hline & Beta Before & Beta After \\
\hline Mean & 632.625 & 743.125 \\
\hline Variance & 280739.125 & 224851.8393 \\
\hline Observations & 8 & 8 \\
\hline Pearson Correlation & 0.237225587 & \\
\hline Hypothesized Mean Difference & 0 & \\
\hline df & 7 & \\
\hline t Stat & -0.502800961 & \\
\hline $\mathrm{P}(\mathrm{T}<=\mathrm{t})$ one-tail & 0.315267166 & \\
\hline t Critical one-tail & 1.894578605 & \\
\hline $\mathrm{P}(\mathrm{T}<=\mathrm{t})$ two-tail & 0.630534333 & \\
\hline t Critical two-tail & 2.364624252 & \\
\hline \multicolumn{3}{|c|}{ Paired t-Test for Before and After Delta } \\
\hline & Delta Before & Delta After \\
\hline Mean & 744.5 & 386.375 \\
\hline Variance & 112743.1429 & 83050.83929 \\
\hline Observations & 8 & 8 \\
\hline Pearson Correlation & 0.604452096 & \\
\hline Hypothesized Mean Difference & 0 & \\
\hline df & 7 & \\
\hline t Stat & 3.608078927 & \\
\hline $\mathrm{P}(\mathrm{T}<=\mathrm{t})$ one-tail & 0.004323133 & \\
\hline t Critical one-tail & 1.894578605 & \\
\hline$P(T<=t)$ two-tail & 0.008646265 & \\
\hline t Critical two-tail & 2.364624252 & \\
\hline
\end{tabular}

Table 3: Paired t-Test results for data from Table 2.

\begin{tabular}{|l|l}
\hline Figure No. & Figure description
\end{tabular}

Figures 6-13 These figures represent the data analysis obtained from using the algorithm created. Three figures show mean voltage of all sessions, number of peaks and standard deviation from mean for Alpha, Beta and Delta waves for all subjects respectively.

Figure 14 and 15 These figures represent lines showing how peak levels of Delta waves change throughout the sessions

Figure 16 and 17 These figures represent lines showing how peak levels of Alpha waves change throughout the sessions

Figure 18 and 19 These figures represent lines showing how peak levels of Beta waves change throughout the sessions

Figures 20-22 All the data collected was represented as a percentage and all subject's data was plotted in one graph for comparison.

Table 4: Figure explanation.

the brain presented by Stroganova et al. [20], increasing a waves apart from decreasing $\delta$ waves helps to compensate for the lower activity and higher activity from the respective hemispheres.

$\beta$ waves are associated with focusing activities [19]. Results illustrated in Figures 18,19 and 21 demonstrate how the subjects' levels of $\beta$ wave peaks increase over time while using the two channel EEG device and BMS device. Due to this promotion of $\beta$ waves, subjects 
Citation: Trevisan AA, Cavallari P, Attard F (2013) A Portable Sonified Neurofeedback Therapy for Autism Spectrum Disorder Patients-An Initial Evaluation. J Neurol Disord 1: 133. doi:10.4172/2329-6895.1000133
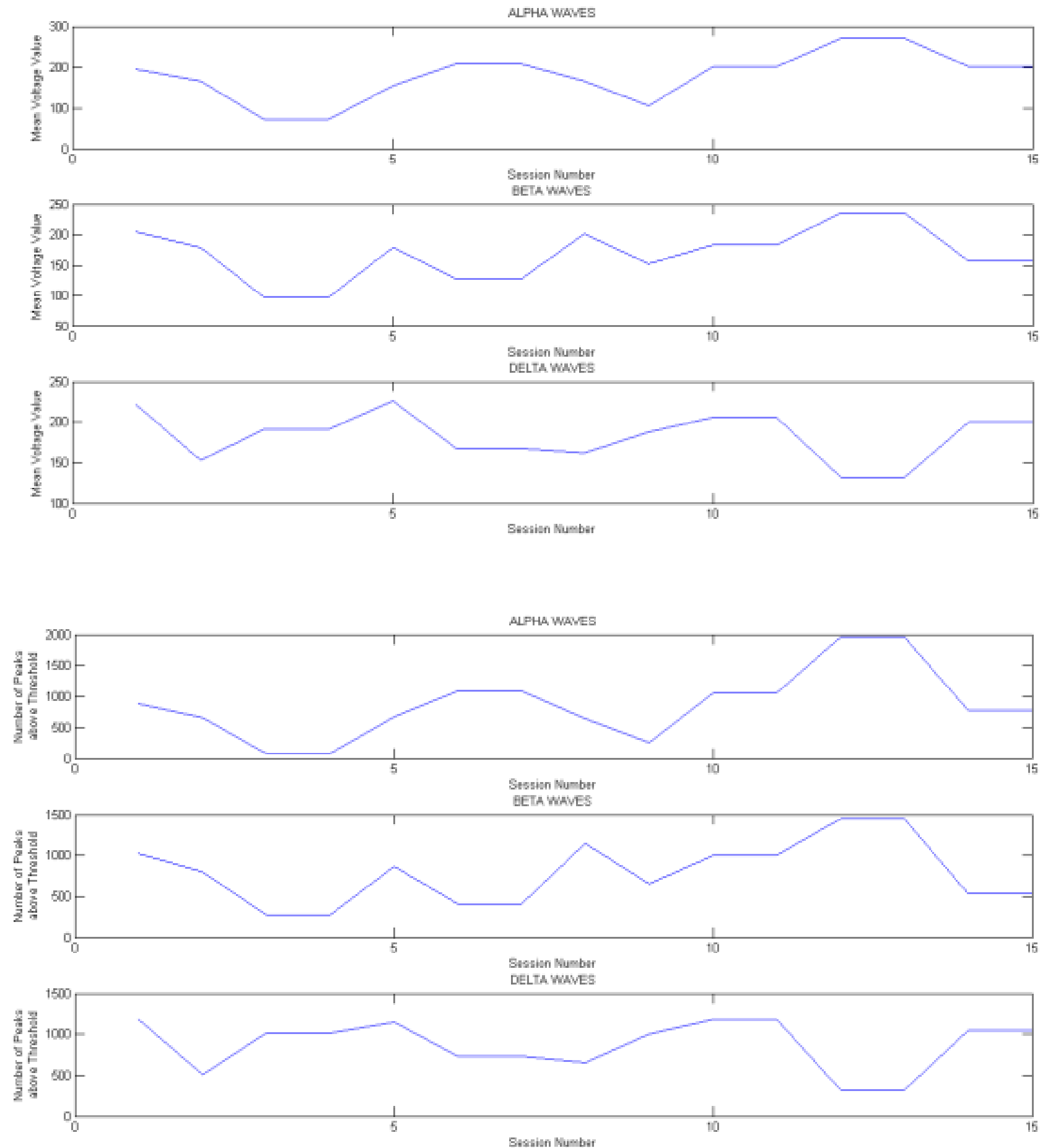

Figure 6: (a) mean voltage of sessions, (b) number of peaks during sessions, (c) Standard deviation from mean voltage for subject 1. 
Citation: Trevisan AA, Cavallari P, Attard F (2013) A Portable Sonified Neurofeedback Therapy for Autism Spectrum Disorder Patients-An Initial Evaluation. J Neurol Disord 1: 133. doi:10.4172/2329-6895.1000133
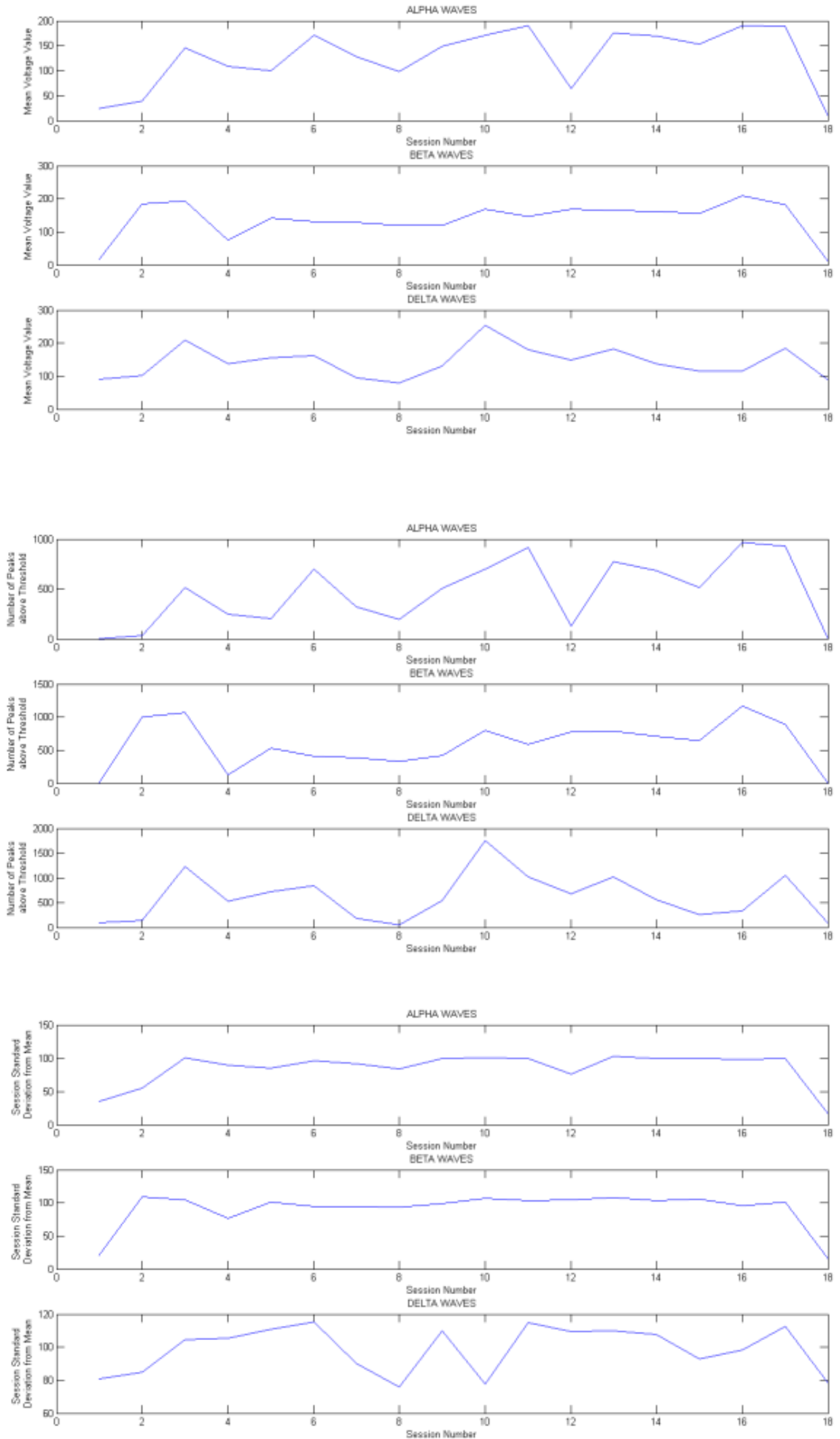

Figure 7: (a) mean voltage of sessions, (b) number of peaks during sessions, (c) Standard deviation from mean voltage for subject 2. 
Citation: Trevisan AA, Cavallari P, Attard F (2013) A Portable Sonified Neurofeedback Therapy for Autism Spectrum Disorder Patients-An Initial Evaluation. J Neurol Disord 1: 133. doi:10.4172/2329-6895.1000133
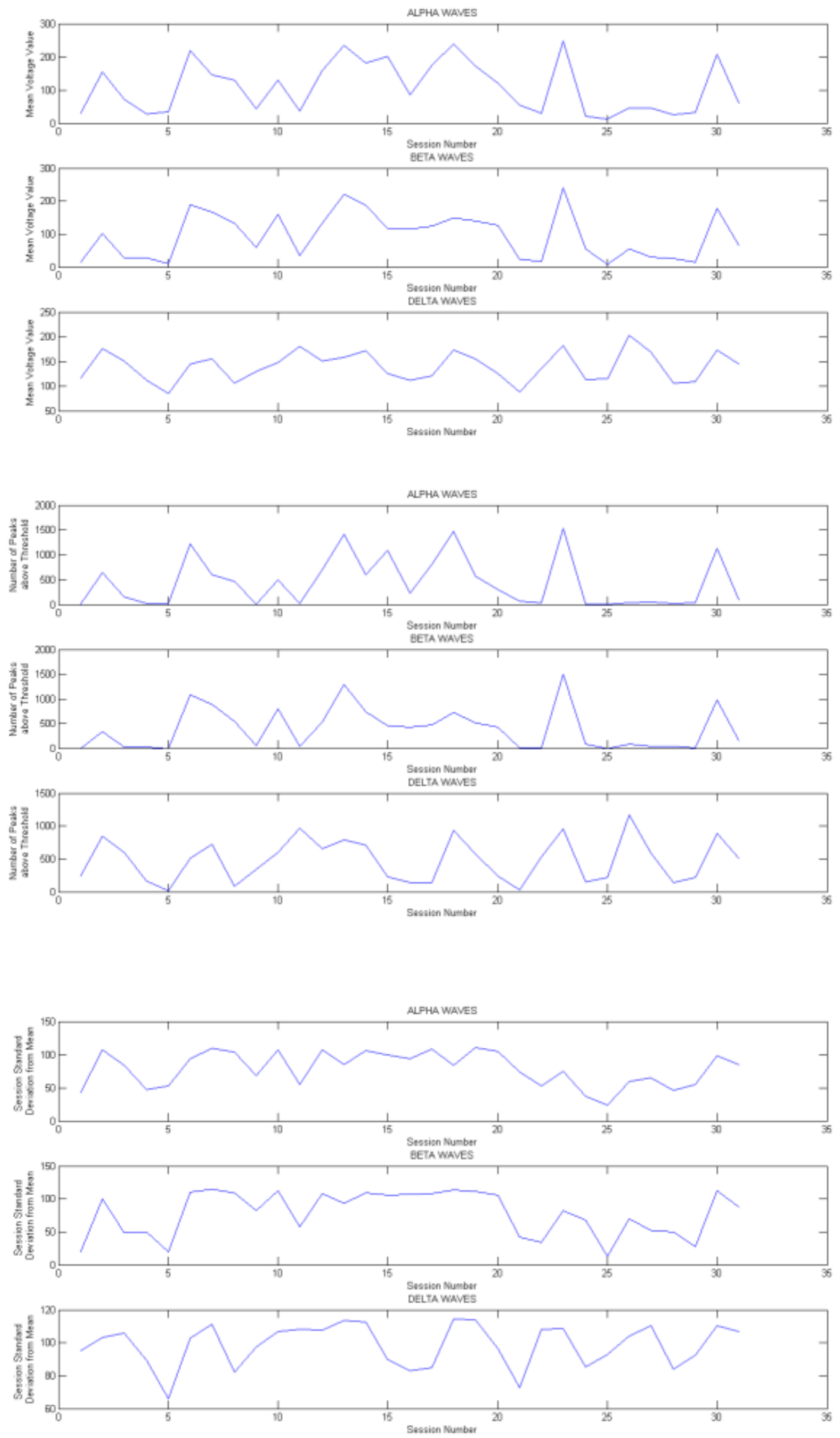

Figure 8: (a) mean voltage of sessions, (b) number of peaks during sessions, (c) Standard deviation from mean voltage for subject 3. 
Citation: Trevisan AA, Cavallari P, Attard F (2013) A Portable Sonified Neurofeedback Therapy for Autism Spectrum Disorder Patients-An Initial Evaluation. J Neurol Disord 1: 133. doi:10.4172/2329-6895.1000133
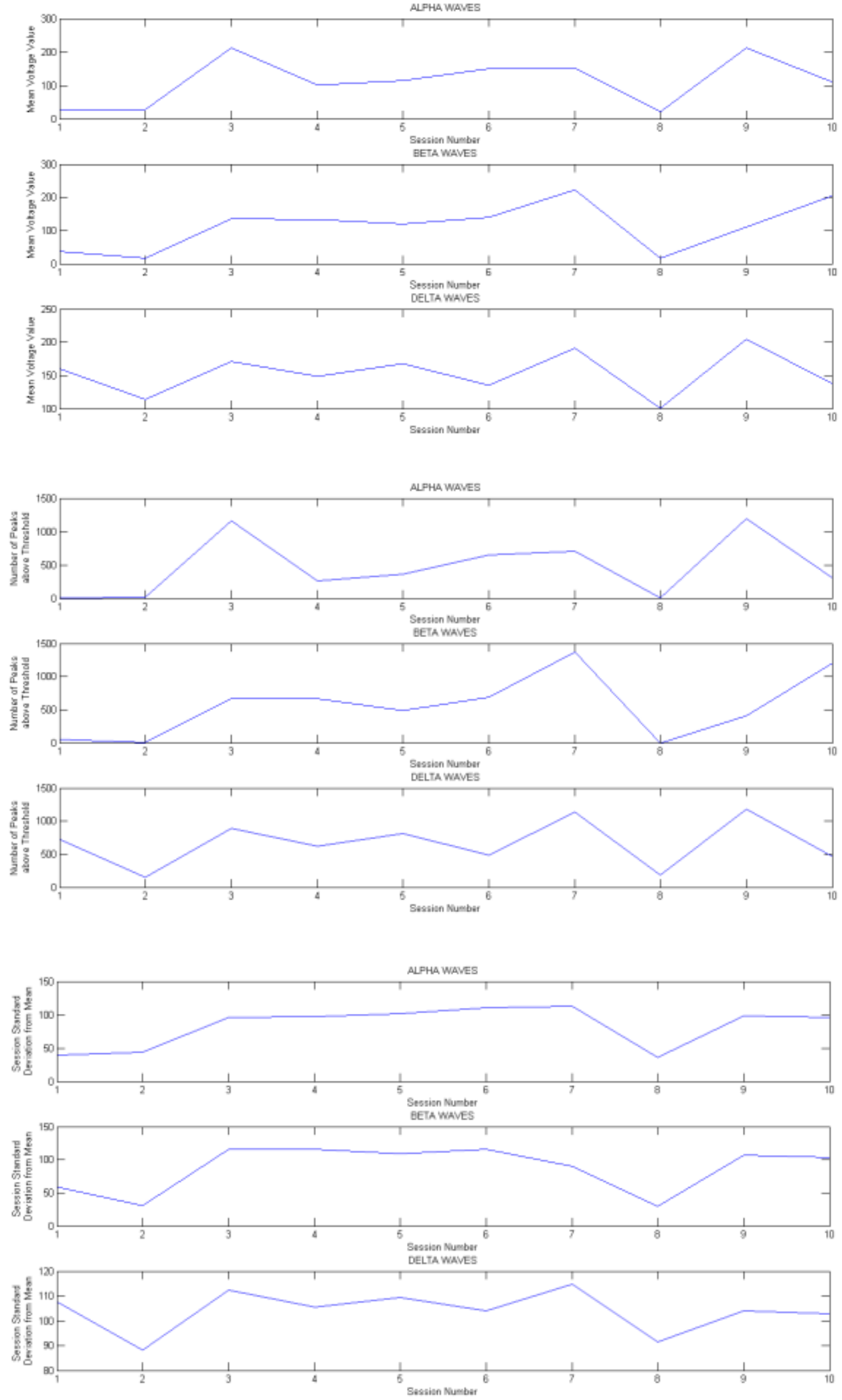

Figure 9: (a) mean voltage of sessions, (b) number of peaks during sessions, (c) Standard deviation from mean voltage for subject 4. 
Citation: Trevisan AA, Cavallari P, Attard F (2013) A Portable Sonified Neurofeedback Therapy for Autism Spectrum Disorder Patients-An Initial Evaluation. J Neurol Disord 1: 133. doi:10.4172/2329-6895.1000133
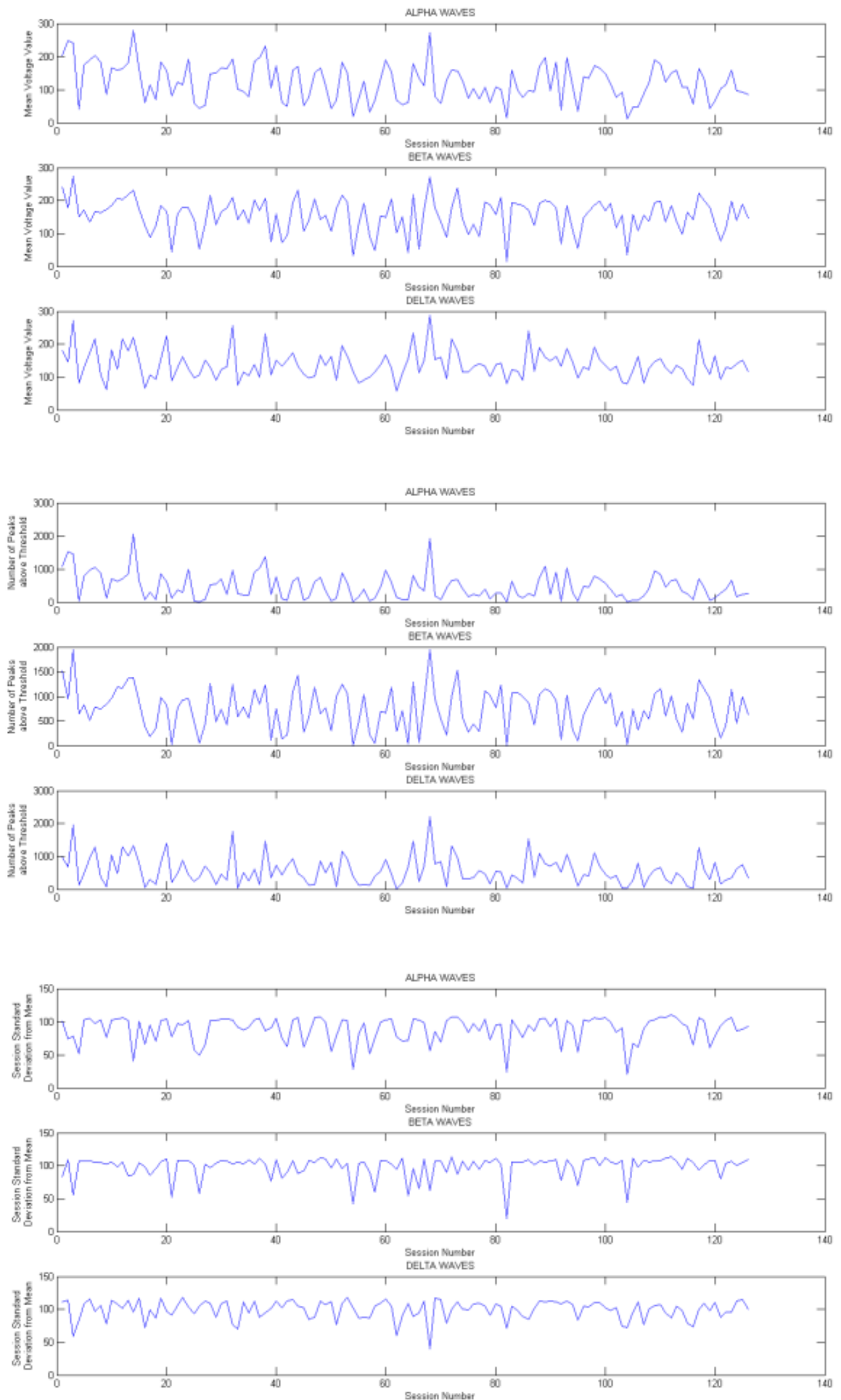

Figure 10: (a) mean voltage of sessions, (b) number of peaks during sessions, (c) Standard deviation from mean voltage for subject 5. 
Citation: Trevisan AA, Cavallari P, Attard F (2013) A Portable Sonified Neurofeedback Therapy for Autism Spectrum Disorder Patients-An Initial Evaluation. J Neurol Disord 1: 133. doi:10.4172/2329-6895.1000133
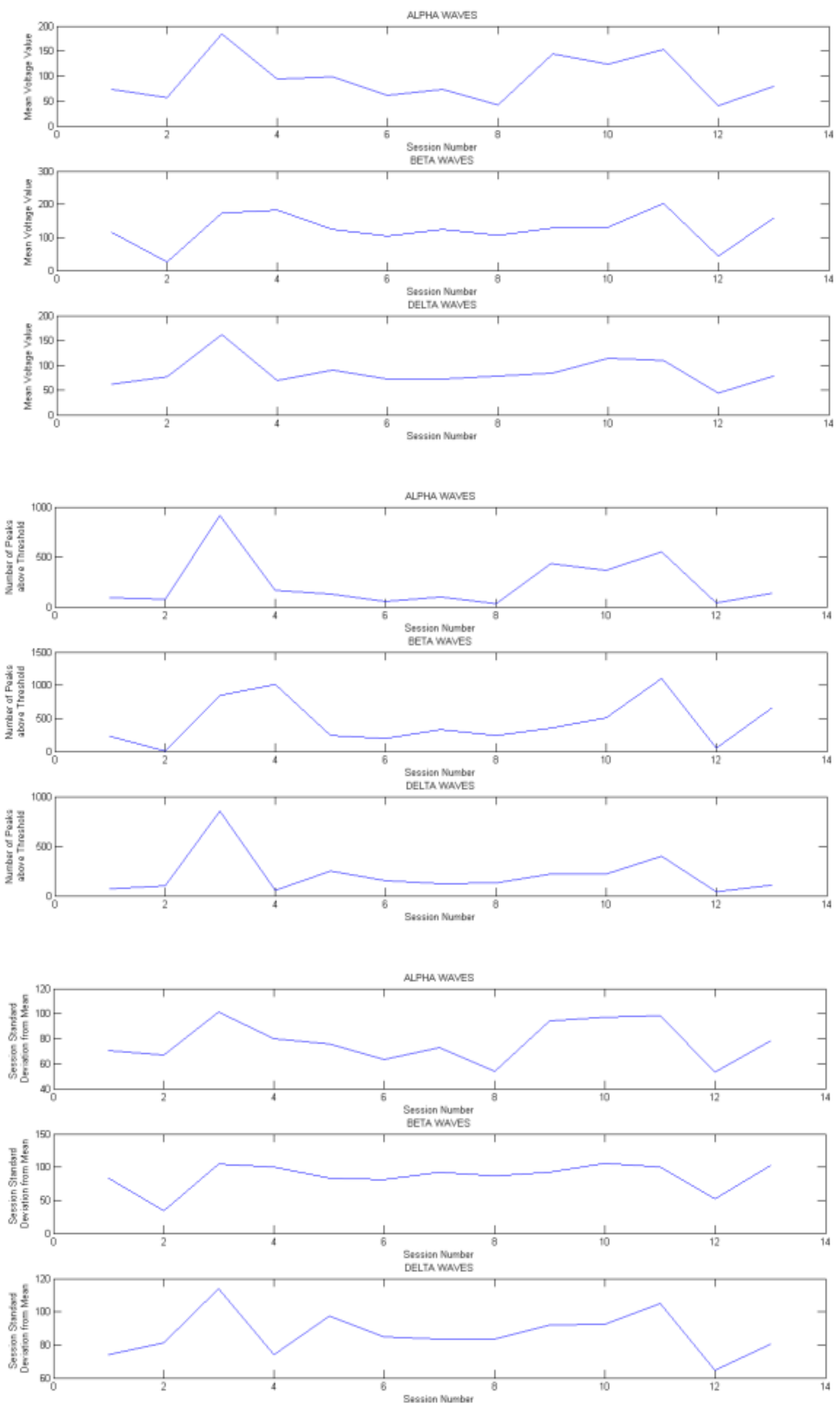

Figure 11: (a) mean voltage of sessions, (b) number of peaks during sessions, (c) Standard deviation from mean voltage for subject 6. 
Citation: Trevisan AA, Cavallari P, Attard F (2013) A Portable Sonified Neurofeedback Therapy for Autism Spectrum Disorder Patients-An Initial Evaluation. J Neurol Disord 1: 133. doi:10.4172/2329-6895.1000133
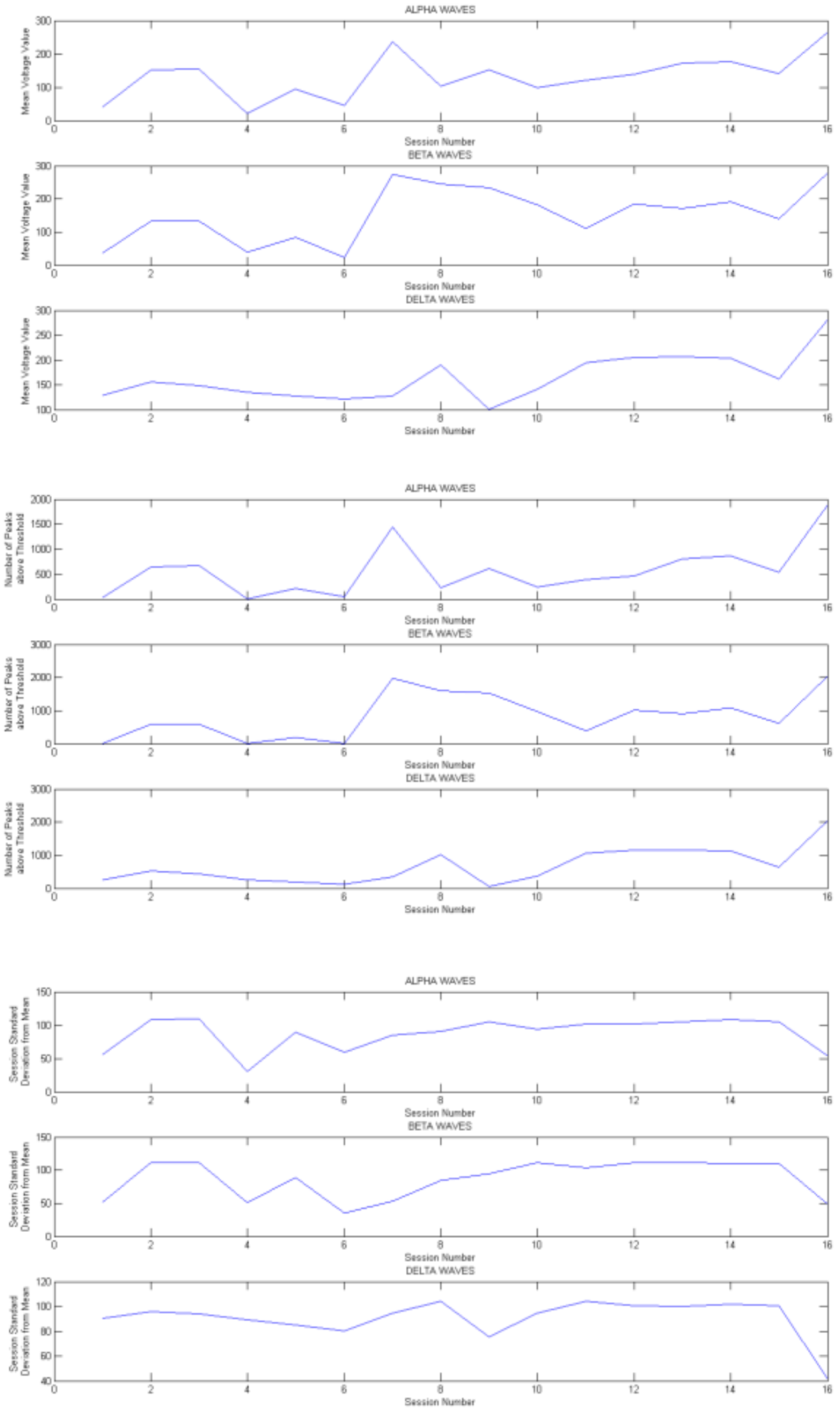

Figure 12: (a) mean voltage of sessions, (b) number of peaks during sessions, (c) Standard deviation from mean voltage for subject 7. 
Citation: Trevisan AA, Cavallari P, Attard F (2013) A Portable Sonified Neurofeedback Therapy for Autism Spectrum Disorder Patients-An Initial Evaluation. J Neurol Disord 1: 133. doi:10.4172/2329-6895.1000133
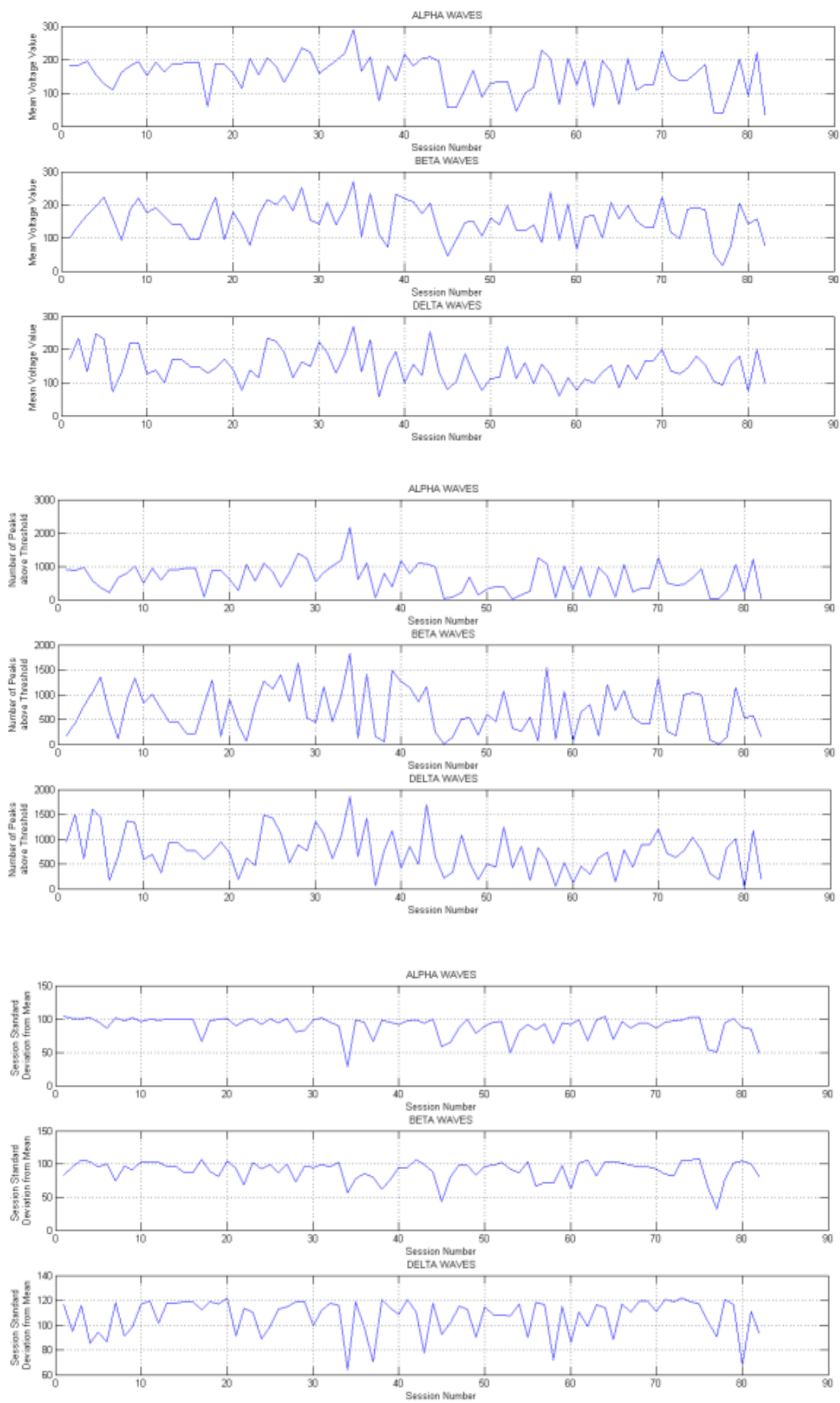

Figure 13: (a) mean voltage of sessions, (b) number of peaks during sessions, (c) Standard deviation from mean voltage for subject 8. 
Citation: Trevisan AA, Cavallari P, Attard F (2013) A Portable Sonified Neurofeedback Therapy for Autism Spectrum Disorder Patients-An Initial Evaluation. J Neurol Disord 1: 133. doi:10.4172/2329-6895.1000133

Page 13 of 14

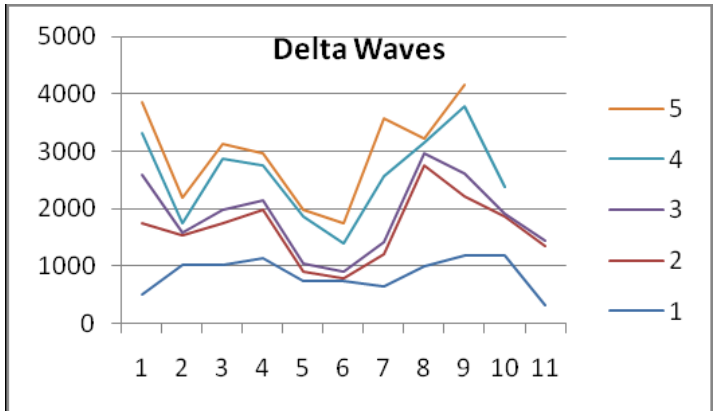

Figure 14: Delta waves in 5 of the subjects in this study(should u labe the axis? Hz vs what?)

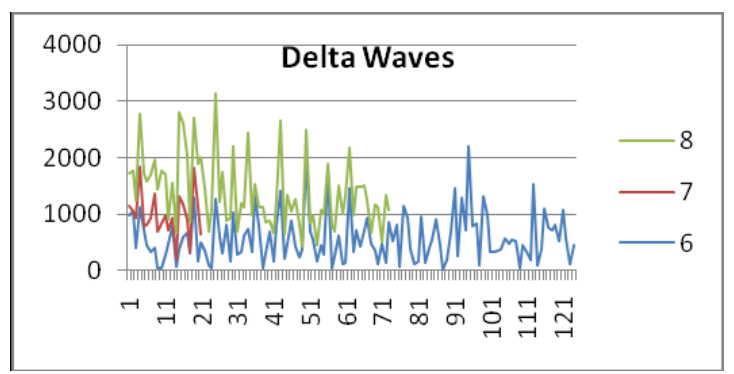

Figure 15: Delta wave peaks in the 3 other subjects.

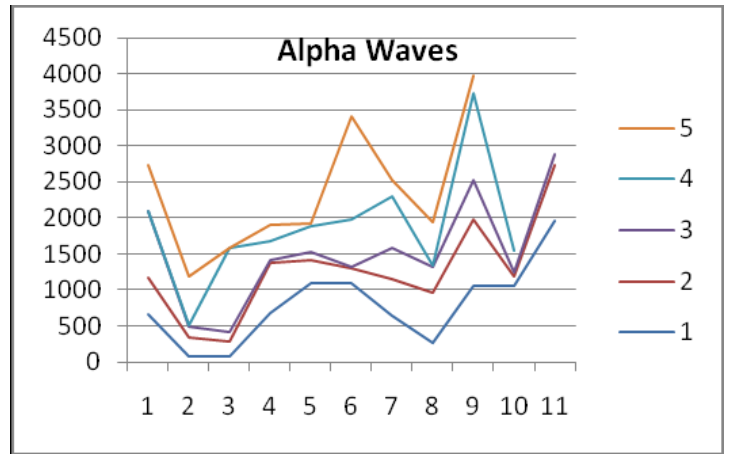

Figure 16: Alpha wave peaks in 5 of the subjects in this study.

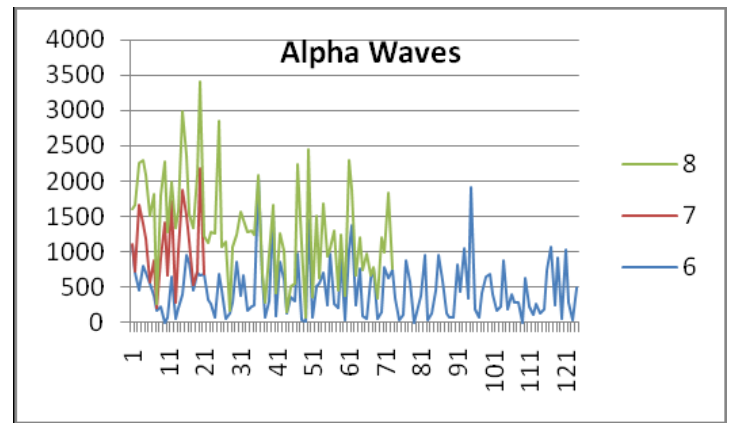

Figure 17: Alpha wave peaks in the other 3 subjects.

tend to be more focused since their levels of $\beta$ wave peaks increase.

Figures 15,17 and 19 represent how $\alpha, \beta$ and $\delta$ wave peaks tend to behave over a longer period of time while using the NF device. These two subjects submitted more daily reports than others thus we have more data on the effect of the BMS device. These two subjects are of more clinical interest due to the opportunity to analyze the longterm effect of the BMS. $\alpha$ and $\beta$ wave peak levels tend to be promoted and increase with respect to previous levels in most of the sessions as demonstrated by the respective figures. However, of more interest in this study is the result obtained in Figure 15 which demonstrates how $\delta$ wave peaks tend to be lowered over time.

A paired t-Test was done on data recorded before and after a period of NF training to test if the Null hypothesis could be rejected [21]. This data represents the peak levels of $\alpha, \beta$ and $\delta$ respectively and is shown in Table 2. Results for this test are shown in Table 3 and it could be concluded that for a before and after, the Null-Hypothesis is not rejected since $t-S t a t$ is $<\mathrm{t}$ Critical one-tail [21]. This implies that statistical difference could or could not have occurred in the period of time. On the other hand, the results demonstrate very positive

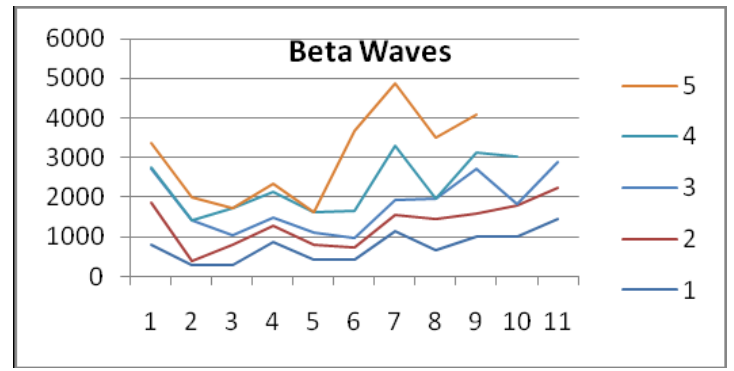

Figure 18: Beta wave peaks in 5 of the subjects in this study.

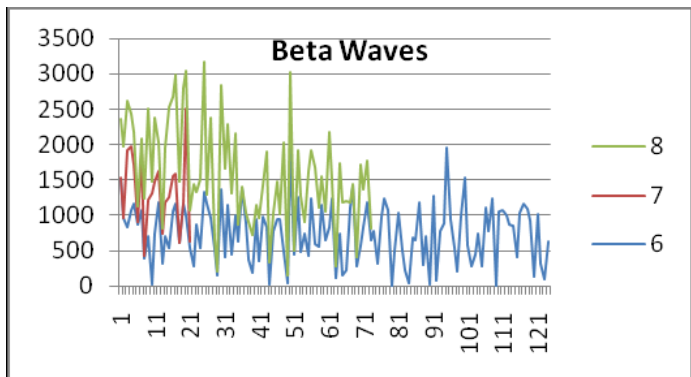

Figure 19: Beta wave peaks in the other 3 subjects in this study.

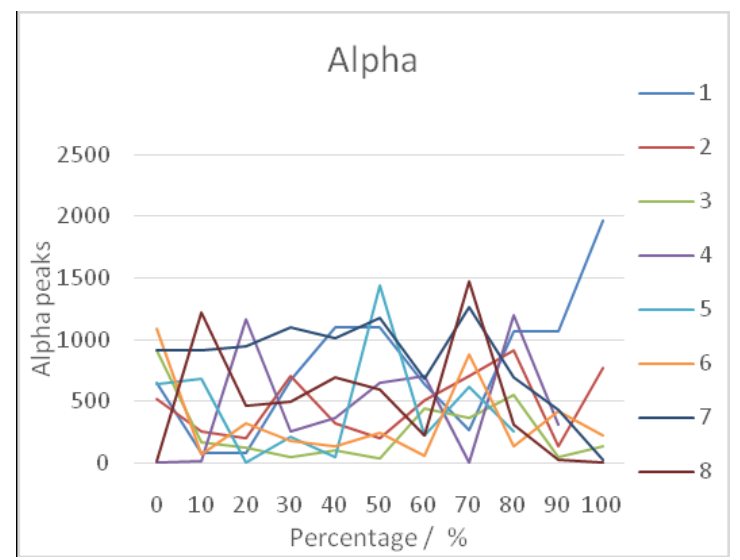

Figure 20: Graph representing Alpha wave peaks of all subject with respect to the percentage of the duration in which analysis was done. 
Citation: Trevisan AA, Cavallari P, Attard F (2013) A Portable Sonified Neurofeedback Therapy for Autism Spectrum Disorder Patients-An Initial Evaluation. J Neurol Disord 1: 133. doi:10.4172/2329-6895.1000133

Page 14 of 14

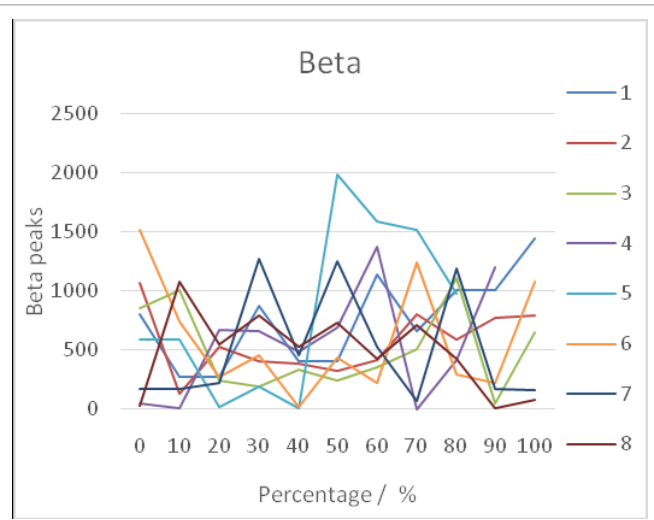

Figure 21: Graph representing Beta wave peaks of all subject with respect to the percentage of the duration in which analysis was done.

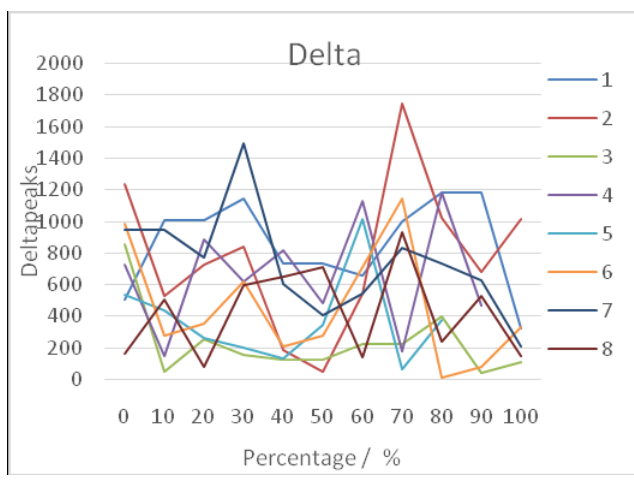

Figure 22: Graph representing Delta wave peaks of all subject with respect to the percentage of the duration in which analysis was done.

statistical relevance for $\beta$ and $\delta$ wave peak levels before and after the NF training period. For the $\beta$ wave peak levels, the Null-Hypothesis is rejected since $\mathrm{t}$-Stat is $>\mathrm{t}$ Critical one-tail and therefore there is statistical difference [21] i.e. $\beta$ wave levels have increased over the period of time. The most important result from this study shows that $\delta$ wave levels have been suppressed and there is statistical difference before and after NF training. In fact, the Null-Hypothesis is rejected since $\mathrm{t}$-Stat is $>\mathrm{t}$ Critical one-tail \& $\mathrm{P}(\mathrm{T}<=\mathrm{t})$ two-tail is smaller than alpha (0.05) which demonstrates that there is statistical difference between before and after data [21].

To summarize the results of this study performed on children diagnosed with ASD, all participants in this trial demonstrated behavioral improvement. Literature states that patients suffering from ASD tend to have atypical functional brain asymmetries which are the cause of different activity in hemispheres causing lower $\alpha$ and $\beta$ waves while keeping high $\delta$ waves activity. The children who participated in this study used the BMS device and the result was that $\delta$ waves were suppressed and $\alpha$ and $\beta$ waves were promoted leading to a lower peak count of $\delta$ waves and higher peak counts of $\alpha$ and $\beta$ waves respectively.

\section{Conclusion}

The presented study gave positive and coherent results. The use of the BMS for children suffering from ASD showed significant improvement of the child's behaviour and interaction. A paired t-Test also supported the main aim of the study, i.e. to suppress $\delta$ waves in the subject's brain activity. The results show that there is statistical difference before and after the NF training period. To support this statement, apart from all the analysis done, close relatives of the children subjected to this paper also confirmed the significant improvement in their children's social behaviour. As for future work, comparing the BMS music therapy together with other complimentary therapies should be encouraged.

\section{Conflict of Interest}

The product used in this medical trial is developed by AAT Research which funded this study in collaboration with the Università Degli Studi Di Milano.

\section{References}

1. (2005) European Commission. Some elements about the prevalence of Autism Spectrum Disorders (ASD)

2. Haqa I, Couteurb AL (2004) Autism spectrum disorder. Medicine.

3. Lofthouse N, Hendren R, Hurt E, Arnold LE, Butter E (2012) A review of complementary and alternative treatments for autism spectrum disorders. Autism Res Treat 2012: 870391.

4. McGee JP, Lord C (2001) Educating Children With Autism. National Academy Press, Washington DC, USA

5. Myers SM, Johnson CP; American Academy of Pediatrics Council on Children With Disabilities (2007) Management of children with autism spectrum disorders. Pediatrics 120: 1162-1182.

6. Cornew L, Roberts TP, Blaskey L, Edgar JC (2012) Resting-state oscillatory activity in autism spectrum disorders. J Autism Dev Disord 42: 1884-1894.

7. Lubar JF (1997) Neocortical dynamics: implications for understanding the role of neurofeedback and related techniques for the enhancement of attention. Appl Psychophysiol Biofeedback 22: 111-126.

8. Arns M, Drinkenburg W, Leon Kenemans J (2012) The effects of QEEGinformed neurofeedback in ADHD: an open-label pilot study. Appl Psychophysiol Biofeedback 37: 171-180.

9. Lansbergen MM, van Dongen-Boomsma M, Buitelaar JK, Slaats-Willemse D (2011) ADHD and EEG-neurofeedback: a double-blind randomized placebocontrolled feasibility study. J Neural Transm 118: 275-284.

10. Pineda JA, Brang D, Hecht E, Edwards L, Carey S, et al. (2008) Positive behavioral and electrophysiological changes following neurofeedback training in children with autism. Research in Autism Spectrum Disorders 2: 557-581.

11. Holtmann M, Steiner S, Hohmann S, Poustka L, Banaschewski T, et al. (2011) Neurofeedback in autism spectrum disorders. Dev Med Child Neurol 53: 986993.

12. Gruzelier JH, Foks M, Steffert T, Chen MJ, Ros T (2013) Beneficial outcome from EEG-neurofeedback on creative music performance, attention and wellbeing in school children. Biol Psychol.

13. Trevisan AA, Jones L (2011) Brain Music System: Standardized Brain Music Therapy. London Metropolitan University.

14. Trevisan AA, Jones L (2011) Brain Music System: Brain Music Therapy Based on Real-Time Sonified Brain Signals.

15. Ma X, Guan X (2005) LORETA-contracting algorithm for solving EEG source distribution problems. The International Journal for Computation and Mathematics in Electrical and Electronic Engineering 24: 821-828.

16. Pascual-Marqui RD, Michel CM, Lehmann D (1994) Low resolution electromagnetic tomography: a new method for localizing electrical activity in the brain. Int J Psychophysiol 18: 49-65.

17. (2012) US National Institutes of Health. Clinical Trials.

18. (2012) Government of Yukon. Multiple Sclerosis (MS) Clinical Trial Selection Process.

19. Teplan M (2002) Fundamentals of EEG Measurement. Measurement Science Review.

20. Stroganova TA, Nygren G, Tsetlin MM, Posikera IN, Gillberg C, et al. (2007) Abnormal EEG lateralization in boys with autism. Clin Neurophysiol 118: 18421854.

21. Wright DB (1997) Understanding Statistics: An introduction for the socia Sciences. London: Sage Publications Ltd. 